\title{
Modelling of Electrical Spring for Voltage, Power Factor Correction and Improving Power Stability
}

\author{
Neha Agrawal, Garvit Gupta \\ Department of Electrical Engineering, Swami Keshvanand Institute of Technology, Management \& \\ Gramothan, Jaipur-302017 (INDIA) \\ Email: neha14agrawal91@gmail.com,garvitgupta5@gmail.com \\ Received 11.02.2021, received in revised form 17.05.2021, accepted 28.05.2021
}

\begin{abstract}
Theobjective of this paper is to develop fuzzy logic controller techniques to improve power system stability power factor and voltage. In these, we are using ES 'Electric Spring' which called as smart gird device which used to dispatch Real and Imaginary power in the system which is connected between the Gird and Load or demand and supply. Fuzzy optimization techniques compared with other conventional technologies and adopted best results. The damping controller is designed by using the fuzzy logic controller. The main conclusions have been drawn on the suitability of the optimization technique. This control system also provides an opportunity for better usage of Electric Spring thereby improving Quality Voltage and Quality Power along with Renewable Energy Microgrid.
\end{abstract}

Keywords- Power Quality, Fuzzy logic controller(FZC), ES 'Electric spring' Demand-side management(DSM), Renewable Energy Sources(RES)

\section{INTRODUCTION}

Power quality can be defined as any power problem faced by the deviation of frequency, current or voltage that leads to the customer's equipment system failure. Maintaining the efficiency of electric power to keep it within acceptable limits has always been challenging. The degradation of power quality is mainly due to the use of power electronics devices that act as a nonlinear load. In the distribution systems, low power quality results in numerous problems such as higher power losses, harmonics, voltage sag and swells, poor distortion and displacement factor. Recent developments in communications, digital electronics and control systems have rapidly increased the number of critical loads needed for proper operation by the ideal sinusoidal supply voltage. So it became important to provide some kind of compensation to meet the standards-proposed limits. Various FACTS devices are available here for DVR, SSSC, STATCOM, UPQC, DSTATCOMetc...., to boost power efficiency,

\section{PROBLEM IDENTIFICATION}

A. The deficiencies occurring in the determination of nonlinear load result in low-quality power.
B. Low-frequency oscillations are found when relatively weak tie lines interconnect wide power systems. FACTS (Flexible AC Transmission Systems ) devices play the role of a very cruise for the present development in the field of power electronics.FACTS devices can control the structure of the system very fast and this FACTS function can be used to increase the reliability of a power system. To deflate electromechanical oscillations in the power system, the extra controller can be used with FACTS devices to boost system damping. The damping controller is called the supplementary controller. In the speed deviation process, the damping controllers are designed to produce electrical torque.

C. In the power system network, power demand is variable means load variance critical load, nonlinear loads, non-critical loads always produce suppression of power quality.

D. PQ disruptions such as harmonics and starting and ending unbalancing due to any faults (Symmetrical/Asymmetrical) in the power system network in all phase load currents.

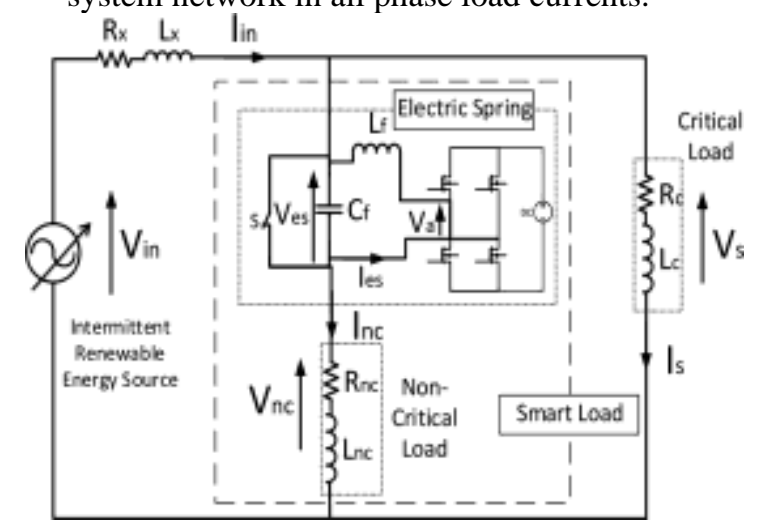

Fig.1 Layout for Electric Spring

\section{BRIEF OVERVIEW OF IMPROVISEDES}

To form a new generation of smart loads, the electric spring is connected in series with the non-critical loads. These smart loads are designed to reduce the power imbalance in a control system. By illustrating similarities to a conventional mechanical spring, the Electric Spring idea was introduced. It could be 
realized via an inverter in a RES is driven microgrid and non-critical loads are connected in series, such as Vacuum cleaners, electric heaters, AC, and refrigerators as shown in Figure 1, to consider a smart load. Critical loads like the protection system of a building are linked in shunt to this smart load.

\section{IMPROVISED CONTROL SCHEME}

By using the Fuzzy Logic Controller Alogritham technique be can solve Complex structures and decision processes. It can be simple than Complex mathematical equations. This algorithm is based on logical rules like AND logic, OR logic only. When we provide voltage input of the Fuzzy logic control system, the power factor is established. if then condition used in the rule book.

We have used Mamdani in Fuzzy inference systems. MATLAB uses to import and export as the basis for the implementation of fuzzy. There are 49 rules for applying fuzzy, some of which are

1. If (e is NB) and (Ce is NB) then the (o is NB)

2. If (e is NB) and (Ce is NM) then the (o is NB) Other rules are represted by table 1 .

Table-1 Membership function during various voltage condition.

\begin{tabular}{|l|l|l|l|l|l|l|l|}
\hline e/ce & NB & NM & NS & ZE & PS & PM & PB \\
\hline NB & NB & NB & NB & NB & NM & NS & ZE \\
\hline NM & NB & NB & NB & NM & NS & ZE & PS \\
\hline NS & NB & NB & NM & NS & ZE & PS & PM \\
\hline ZE & NB & NM & NS & ZE & PS & PM & PB \\
\hline PS & NM & NS & ZE & PS & PM & PB & PB \\
\hline PM & NS & ZE & PS & PM & PB & PB & PB \\
\hline PB & ZE & PS & PM & PB & PB & PB & PB \\
\hline
\end{tabular}

\section{COMBINATION OF ELECTRIC SPRING AND FACTS DEVICES}

Electric springs (ES) are an emerging technology that tackles the challenge of the volatility of the power grid resulting from the growing infiltration of renewable energy sources delivered intermittently. To get the best power quality improvement in combining various renewable energy sources (microgrid) at grid problems combination of electric spring and FACTS devices gives the best performance characteristics.

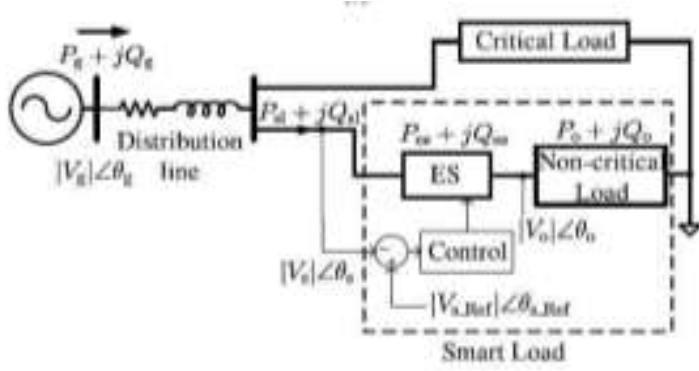

Fig.2 Diagramatical Representation of Power System (ES installed)

\section{PROPOSED TECHNIQUE}

Research and development are a non-stopping method in this work. There is always a chance of further progress with every study work carried out and several paths are opened for further research. The future work that must be done with FACTS controllers in the field of power system stability improvement has been described and listed below.

\subsection{Fuzzy control strategies:}

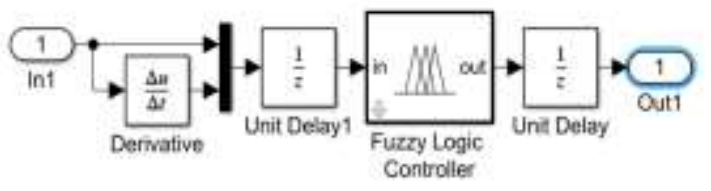

Fig.3. Fuzzy control interference system

\subsection{Fuzzy PID control strategies:}

Because of the above features, the control scheme is always treated as the backbone to get the desired functionality. In present days optimization techniques (intelligent controllers) are playing a vital role to operate power electronic converter circuits (specially to decide switching operation). To manage hybrid power generations, require at least two control schemes in closed-loop manners. Some of the new supervisory control strategies are discussed briefly in this section. One of the easy method used for mapping input and output space by fuzzy logic. The initial point for all is mapping input to output.

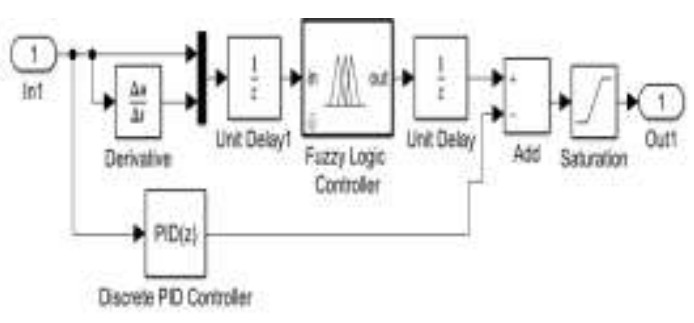

Fig.6 Fuzzy PID control interference system

\section{SIMULINK MODEL}

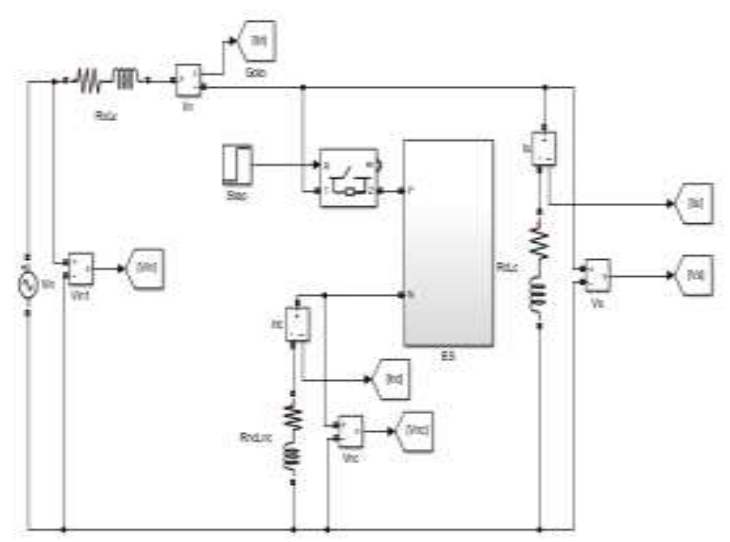

Fig.5 Modeling diagram for ES 
7.1 Proposed circuit of Simulink model with FLC

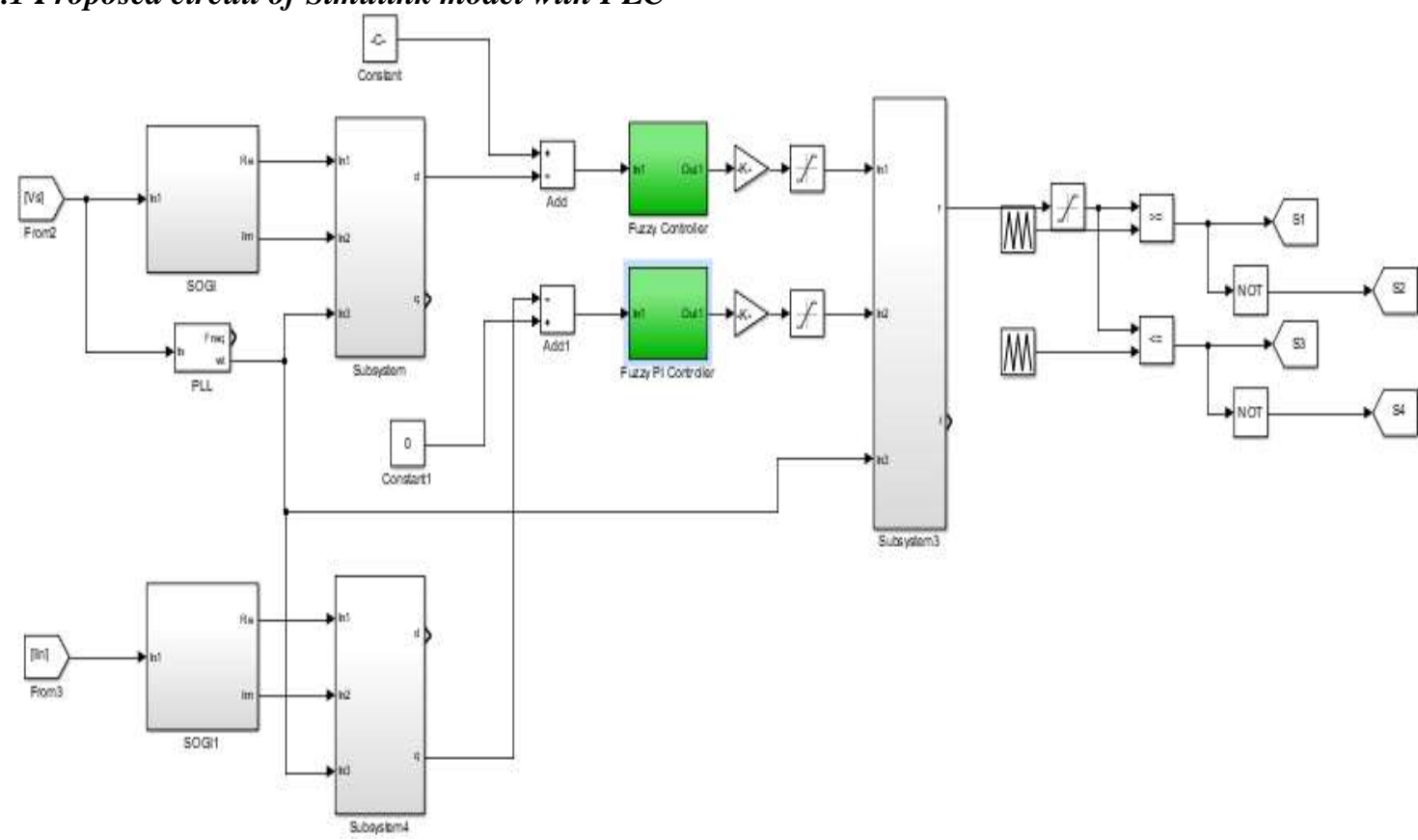

Fig. 6 Simulink model with FLC

7.2 Proposed circuit of Simulink model of output
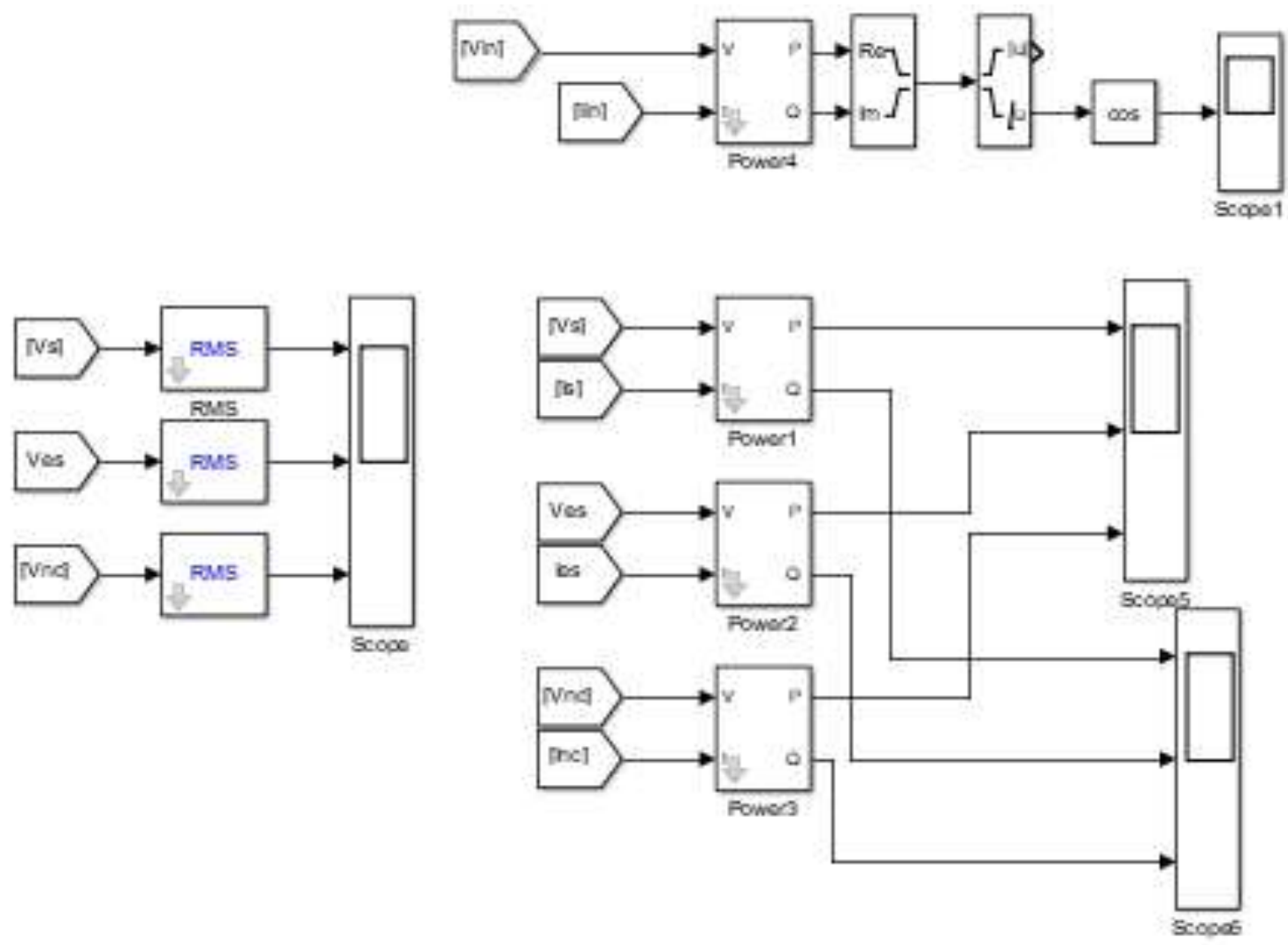

Fig.7:Simulink model of output

\section{SIMULATION RESULTS}

8.1 Proposed Simulink circuit of electrical spring

Here we are discussing our proposed topology at two voltages: 


\subsubsection{Overvoltage Electric Spring at $\mathrm{t}=0.5 \mathrm{Sec}$.}

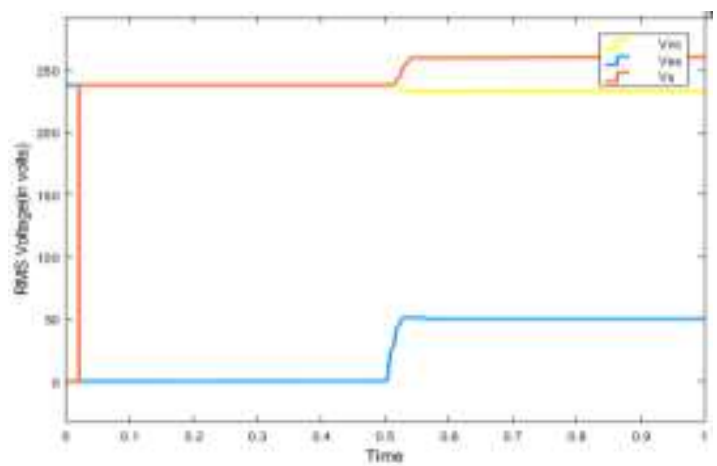

Fig.10 Overvoltage Condition: Output waveform for RMS line voltage, noncritical load voltage and ES.

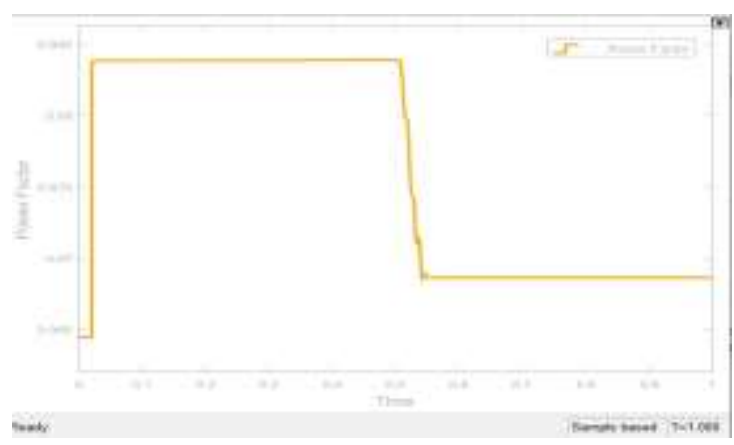

Fig.11 Overvoltage Condition: Output waveform for Power factor of the system.

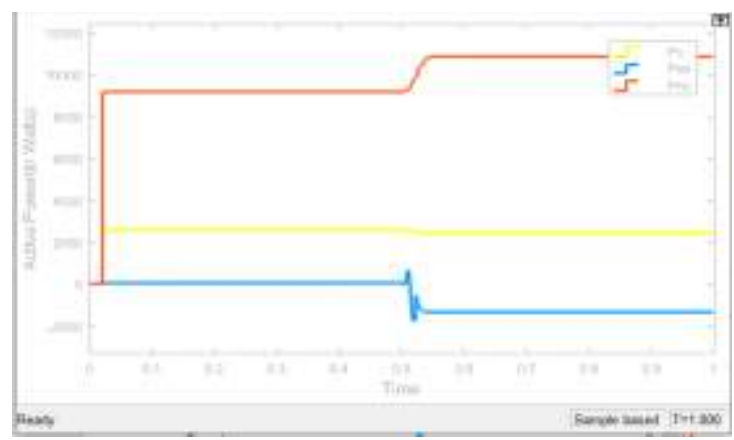

Fig.12 Overvoltage Condition: Output waveform for Active power of the system.

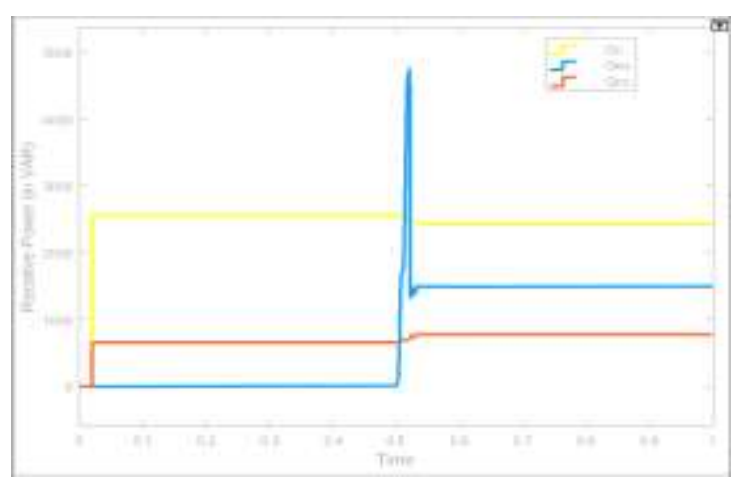

Fig.13 Overvoltage Condition: Output waveform for Reactive power of the system.
8.1.2 Under voltage Electric Spring is on at $\mathbf{t}=\mathbf{0 . 5}$ Sec.

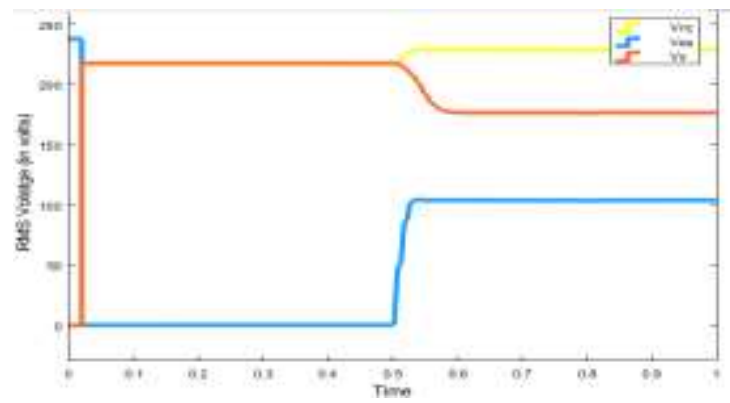

Fig.14 Undervoltage condition: Output waveform for ES voltage noncritical load voltage and RMS line voltage.

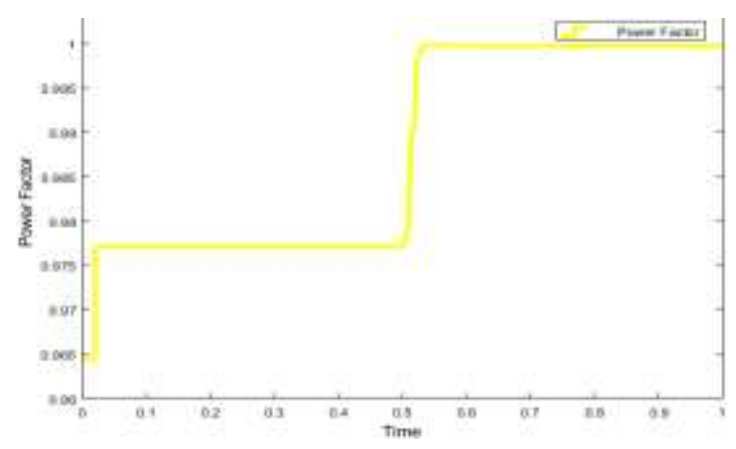

Fig.15 Undervoltage condition: Output waveform for Power factor of the system.

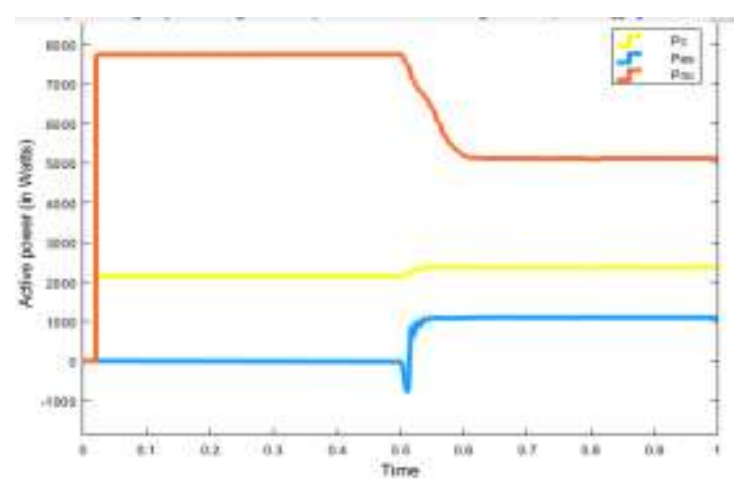

Fig.16 Undervoltage condition: Output waveform for Active power of the system.

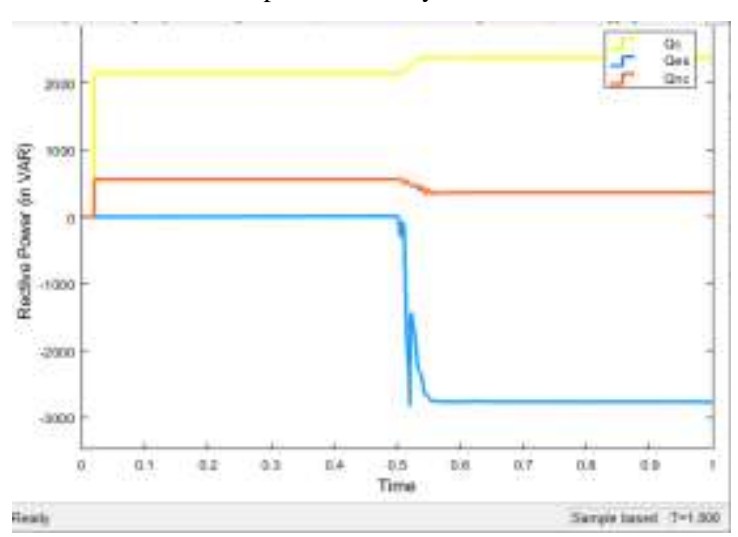

Fig.17 Undervoltage condition: Output waveform for Reactive power of the system. 


\section{COMPARISON TABLE}

Table 2 Power factor during various voltage conditions.

\begin{tabular}{|c|c|c|}
\hline \multirow{2}{*}{ Type of controller } & \multicolumn{2}{|c|}{ Power factor } \\
\cline { 2 - 3 } Conventional ES & 0.965 & $\begin{array}{c}0.965 \text { to almost } \\
\text { unity }\end{array}$ \\
\hline Improvised ES & 0.984 & $\begin{array}{c}0.976 \text { to almost } \\
\text { unity }\end{array}$ \\
\hline Proposed & 0.99 & $\begin{array}{c}0.98 \text { to almost } \\
\text { unity }\end{array}$ \\
\hline
\end{tabular}

\section{CONCLUSION}

Electric spring, together with renewable energy power grids, was proposed to overcome the issues related to voltage and energy stability. Furthermore, it was shown in this work, that improvised electric spring (a) maintained a reference voltage of 230 volts (b) retained constant power for critical loads (c) increased the device overall power factor in comparison with traditional power spring. When compared with the traditional method, the proposed method improves input voltage and input current by $1.5 \%$. It has been demonstrated through simulation and improvement of the power quality. Improved control system with reactive power injected is worth over the conventional electrical spring. If the noncritical building load is fitted with an electrical spring, the electric spring can also be built-in future home appliances. They can provide voltage and power stability and instant electricity correction in the microgrid of renewable energy. It could be applied without relying on information and communication technologies. It could have specific demand-side management (DSM) solution.

\section{REFERENCES}

[1] S. Y. Hui, C. K. Lee, and F. F. Wu, "Electric springs - a new smart grid technology," IEEE Transactions on Smart Grid, vol. 3, no. 3, pp. 1552-1561, Sept 2012.

[2] S. Hui, C. Lee, and F. Wu, "Power control circuit and method for stabilizing a power supply," US 2012/0080420 A1 Apr. 5, 2012.

[3] JayantikaSoni, Sanjib Kumar Panda "Electric Spring for Voltage and Power Stability and Power Factor Correction" IEEE Transactions on Industry Applications, Vol. 53, No. 4 July/August 2017.

[4] C. K. Lee, B. Chaudhuri, and S. Y. Hui, "Hardware and control implementation of electric springs for stabilizing future smart grid with intermittent renewable energy sources," IEEE Journal of Emerging and Selected Topics in Power Electronics, vol. 1, no. 1, pp. 18-27, March 2013.

[5] C. K. Lee, K. L. Cheng, and W. M. Ng, "Load characterization of electric spring," in 2013 IEEE Energy Conversion Congress and Exposition, Sept 2013, pp. 4665 4670 .

[6] J. Soni, K. R. Krishnanand, and S. K. Panda, "Load-side demand management in buildings using controlled electric springs," in IECON 2014 - 40th Annual Conference of the IEEE Industrial Electronics Society, Oct 2014, pp. 53765381.

[7] C. K. Lee and S. Y. . .Hui, "Reduction of energy storage requirements in future smart grid using electric springs," IEEE Transactions on Smart Grid, vol. 4, no. 3, pp. 1282
1288, Sept 2013

[8] C. K. Lee, S. C. Tan, F. F. Wu, S. Y. R. Hui, and B Chaudhuri, "Use of Hooke's law for stabilizing future smart grid - the electric spring concept," in 2013 IEEE Energy Conversion Congress and Exposition, Sept 2013, pp. 52535257.

[9] D. M. Jones, "Power factor correction on distribution systems," Journal of the American Institute of Electrical Engineers, vol. 39, no. 7, pp. 648-657, July 1920

[10] A. Ghosh and A. Joshi, "A new approach to load balancing and power factor correction in the power distribution system," IEEE Transactions on Power Delivery, vol. 15, no. 1, pp. 417-422, Jan 2000.

[11] S. R. Arya, B. Singh, A. Chandra, and K. Al-Haddad, "Power factor correction and zero voltage regulation in distribution system using DSTATCOM," in 2012 IEEE International Conference on Power Electronics, Drives and Energy Systems (PEDES), Dec 2012, pp. 1-6.

[12] D. Masand, S. Jain, and G. Agnihotri, "Control algorithms for distribution static compensator," in Industrial Electronics, 2006 IEEE International Symposium on, vol. 3, 2006, Conference Proceedings, pp. 1830-1834.

[13] K. R. Krishnanand, S. M. F. Hasani, J. Soni, and S. K. Panda, "Neutral current mitigation using controlled electric springs connected to microgrids within the built environment," in Proc. 2014 IEEE Energy Convers. Congr. Expo., Sep. 2014, pp. 2947-2951.

[14] J. Soni and S. K. Panda, "Electric spring for voltage and power stability and power factor correction," in Proc. 2015 9th Int. Conf. Power Electron., Jun. 2015, pp. 2091-2097.

[15] S. C. Tan, C. K. Lee, and S. Y. Hui, "General steady-state analysis and control principle of electric springs with active and reactive power compensations," IEEE Trans. Power Electron., vol. 28, no. 8, pp. 3958-3969, Aug. 2013.

[16] Y. Shuo, T. Siew-Chong, L. Chi-Kwan, and S. Y. R. Hui, "Reducing three-phase power imbalance with electric springs," in Proc. IEEE 5th Int. Symp. Power Electron. Distrib. Gen. Syst., 2014, pp. 1-7.

[17] Y. Shuo, S. C. Tan, C. K. Lee, and S. Y. R. Hui, "Electric spring for power quality improvement," in Proc. 2014 IEEE Appl. Power Electron. Conf. Expo., Mar. 2014, pp. 21402147.

[18] K. T. Mok, S. C. Tan, and S. Y. R. Hui, "Decoupled power angle and voltage control of electric springs," IEEE Trans. Power Electron., vol. 31, no. 2, pp. 1216-1229, Feb. 2016.

[19] Q. Wang, M. Cheng, and Z. Chen, "Steady-state analysis of electric springs with a novel delta control," IEEE Trans. Power Electron., vol. 30, no. 12, pp. 7159-7169, Dec. 2015.

[20] R. Zhang, "Control of single-phase power converter in d-q rotating coordinates," US 2003/0076076 A1 Apr. 24, 2003.

[21] R. Zhang, M. Cardinal, P. Szczesny, and M. Dame, "A grid simulator with control of single-phase power converters in the d-q rotating frame," in Proc. IEEE 33rd Annu. Power Electron. Spec. Con., 2002, vol. 3, pp. 1431-1436.

[22] A. Roshan, "A DQ rotating frame controller for single-phase full-bridge inverter used in small distributed generation systems," Master's thesis, Dept. Elect. Comp. Eng. Virginia Tech, Blacksburg, VA, USA, 2006.

[23] M. Ciobotaru, R. Teodorescu, and F. Blaabjerg, "Improved PLL structures for single-phase grid inverters," in Proc. Power Electron. Intell. Control Energy Conserv. Conf., 2005.

[24] S. M. Silva, B. M. Lopes, B. J. C. Filho, R. P. Campana, and W. C. Bosventura, "Performance evaluation of PLL algorithms for single-phase grid-connected systems," in Proc. 39th Annu. Meeting IEEE Ind. Appl. Soc., Oct. 2004, vol. 4, pp. 2259-2263.

[25] M. Ciobotaru, R. Teodorescu, and F. Blaabjerg, "A new single-phase PLL structure based on second-order generalized integrator," in Proc. 2006 37th IEEE Power Electron. Spec. Conf., Jun. 2006, pp. 1-6.

[26] N. R. Chaudhuri, C. K. Lee, B. Chaudhuri, and S. Y. R. Hui, "Dynamic modelling of electric springs," IEEE Trans. Smart Grid, vol. 5, no. 5, pp. 2450-2458, Sep. 2014.

[27] F. Xiao, L. Dong, L. Li, and X. Liao, "A frequency-fixed SOGI based PLL for single-phase grid-connected 
converters," IEEE Trans. Power Electron., vol. 32, no. 3, pp. 1713-1719, Mar. 2016

[28] A. Prudenzi, U. Grasselli, and R. Lamedica, "IEC std. 610003-2 harmonic current emission limits in practical systems: Need of considering loading level and attenuation effects," in Proc. Power Eng. Soc. Summer Meeting, Jul. 2001, vol. 1, pp. 277-282.

[29] C. Graf, J. Maas, T. Schulte, and J. Weise-Emden, "Realtime HILsimulation of power electronics," in Proc. IEEE 34th Annu. Conf. Ind. Electron., Nov. 2008, pp. 2829-2834.

[30] J. J. Poon, M. A. Kinsy, N. A. Pallo, S. Devadas, and I. L. Celanovic, "Hardware-in-the-loop testing for electric vehicle drive applications," in Proc. 2012 27th Annu. IEEE Appl. Power Electron. Conf. Expo., Feb. 2012, pp. 2576-2582.

[31] J. Poon, E. Chai, I. Ulanova, A. Geni, and E. Adzic, "Highfidelity real-time hardware-in-the-loop emulation of PMSM inverter drives," in Proc. 2013 IEEE Energy Convers. Congr. Expo., Sep. 2013, pp. 1754-1758. 